\title{
Perancangan Sistem Basis Data Offline Dokumen Akreditasi Program Studi
}

\author{
Intan Mardiono ${ }^{1}$, Raizummi Fil'aini ${ }^{1}$, Fatin Saffanah Didin ${ }^{1}$ \\ ${ }^{1}$ Program Studi Teknik Industri, Jurusan Teknologi Produksi dan Industri \\ Institut Teknologi Sumatera \\ Jl. Terusan Ryacudu, Lampung 35365 \\ email : intan.mardiono@ti.itera.ac.id \\ doi: https://doi.org/10.31315/opsi.v12i2.3153
}

Received: $22^{\text {nd }}$ December 2019; Revised: $2^{\text {th }}$ December 2019; Accepted: $30^{\text {th }}$ December 2019 Available online: $31^{\text {st }}$ December 2019; Published regularly: December 2019

\begin{abstract}
Accreditation is a government assessment for a Higher Education. Based on the regulation of the minister of education and culture of the Republic of Indonesia number 87 of 2014 article 6, the validity period of the accreditation status and ranking of accredited study programs and tertiary institutions is 5 (five) years. During this time, the institution must prepare the documents used for accreditation. In 2019, the government has implemented changes to the standard accreditation assessment criteria of an institution, the evaluation of accreditation documents refers to several documents, one of them is Study Program Performance Sheet (LKPS) which is recapitulated in an excel. This research focuses on data integration at LKPS. In the LKPS excel data there is a relationship between the data with one another. One of the data that has a relationship is data related to lecturers with tridharma activities. Given that the application of this new rule began in 2019, this research focuses on designing the concept offline, namely Database integration made using Microsoft Access. LKPS analysis results have determined that there are 30 tables of which there are 22 integrated tables and 8 tables that do not have integration.
\end{abstract}

Keywords: Document, Accreditation, Database

\begin{abstract}
ABSTRAK
Akreditasi merupakan suatu penilaian pemerintah untuk suatu instansi perguruan tinggi. Berdasarkan peraturan menteri pendidikan dan kebudayaan Republik Indonesia nomor 87 Tahun 2014 pasal 6, masa berlaku status akreditasi dan peringkat terakreditasi program studi dan perguruan tinggi adalah 5 (lima) tahun. Dalam selang waktu tersebut suatu instansi perguruan tinggi harus mempersiapkan dokumen-dokumen yang digunakan untuk akreditasi. Pertahun 2019 pemerintah telah menerapkan perubahan terhadap standar kriteria penilaian akreditasi sebuah institusi, penilaian dokumen akreditasi tersebut mengacu pada beberapa dokumen, salah satunya Lembar Kinerja Program Studi (LKPS) yang direkap dalam sebuah excel. Penelitian ini fokus dalam integrasi data di LKPS tersebut. Didalam data excel LKPS tersebut terdapat hubungan antara data satu dengan data yang lain. Salah satu data yang memiliki hubungan adalah data terkait dosen dengan kegiatan tridharma. Mengingat bahwa penerapan aturan baru ini dimulai pada tahun 2019, maka penelitian ini fokus dalam perancangan konsep secara offline, yaitu integrasi basis data dibuat dengan menggunakan microsoft access. Hasil analisa LKPS telah ditentukan bahwa terdapat 30 tabel yang mana terdapat 22 tabel yang terintegrasi dan 8 tabel yang tidak memiliki integrasi.
\end{abstract}

Kata Kunci: Dokumen, Akreditasi, Basis Data

\section{PENDAHULUAN}

Akreditasi merupakan suatu assessment pemerintah kepada sebuah instansi perguruan tinggi. Berdasarkan peraturan menteri pendidikan dan kebudayaan Republik Indonesia Nomor 87 tahun 2014 pasal 6, masa berlaku status akreditasi Program Studi dan perguruan tinggi adalah 5 (lima) tahun.
(Indonesia, 2014). Saat ini telah diterapkan peraturan yang baru, yaitu dengan menggunakan kriteria penilaian, yaitu penilaian berdasarkan Lembar Evaluasi Diri (LED) dan Lembar Kinerja Program Studi (LKPS). Di dalam LKPS terekap data hasil kinerja sebuah program studi. Di dalam LKPS tersebut terdapat data yang saling terintegrasi, yaitu data terkait kegiatan yang dilakukan oleh dosen, 
mahasiswa, dan kurikulum yang berlaku di lingkungan kampus.

Di dalam dokumen akreditasi terdebut terdapat data yang saling terkait, data yang saling terkait tersebut merupakan data tentang kegiatan tri dharma dosen dan data- data terkait mahasiswa (prestasi, IPK, serta data perwalian dengan dosen). Dalam menyusun sebuah dokumen lima tahunan tentunya dibutuhkan sebuah arsip untuk menyimpan data-data tersebut sehingga ketika dibutuhkan data tersebut dapat dengan mudah ditemukan serta dapat juga dikelola dengan baik. Pendekatan backup tradisional, seperti mengekspor snapshot dari Database dan menyimpannya di penyimpanan cadangan, perlahan-lahan ditinggalkan (Aryan, Diana, Mohammad, \& Hendro, 2018).

Dokumen akreditasi yang digunakan untuk pengajuan penilaian kepada pemerintah memiliki sebuah integrasi, sehingga dari integrasi tersebut memiliki potensi untuk adanya ketidakkonsistensian data yang telah direkap. Salah satu upaya agar tidak terjadi informasi ganda antara data-data yang terkait tersebut adalah dibuat sebuah Database yang dapat mengampu keseluruhan data untuk akreditasi.

Sistem basis data merupakan sebuah kumpulan data yang terstruktur secara sistematis dan terkelola dengan baik (Wang, Liu, He, \& Wang, 2018). Selain itu di data di dalam borang akreditasi tersebut harus sinkron antara standar satu dengan yang lain. Supaya Database tersebut memiliki akurasi yang tinggi dan tidak memiliki informasi ganda, maka langkah awal yang harus diperhatikan adalah desain hubungan antar entitas (data). Oleh karena itu pertama yang dilakukan adalah mengidentifikasi kebutuhan data antar tabel serta tipe data dari masing-masing data tersebut. Agar lebih efisien dalam membuat sebuah rekapan data di dokumen akreditasi, maka diperlukan pembuatan Database. Mengingat bahwa sistem informasi modern saat ini merupakan suatu sistem informasi yang dinamis dengan pengaturan sistem informasi yang terintegrasi, mudah untuk dioperasikan dan dapat diakses secara cepat dimanapun user tersebut berada (Bolchini, Quintarelli, \& Tanca, 2013).

Modern Database saat ini dikembangkan oleh suatu instansi melalui komputer dengan software agar pengguna komputer tersebut dapat mengakses data tersebut dengan mudah.
Software yang dikembangkan untuk mengelola Database adalah DBMS (Database Management System). DBMS merupakan seperangkat program perangkat lunak yang kompleks yang mengontrol organisasi Database, manajemen, serta simpanan Database (Okereke, 2009). Saat ini perkembangan Database bukan hanya untuk sistem storage data suatu instansi, namun juga digunakan untuk dua kepentingan lain, yaitu; aplikasi pendukung suatu keputusan serta sebagai operasional data.

Dalam mendesain awal sebuah sistem Database diperlukan suatu ketepatan dalam mendesain, yaitu sejauh mana Database tersebut dapat digunakan, apakah Database tersebut merupakan Database yang dapat diandalkan dalam proses dokumentasi kegiatan dosen untuk mendukung dokumen akreditasi atau tidak, mulai dari tampilan hingga cara pengoperasian sistem Database tersebut. Oleh karena itu untuk membuat sebuah sistem basis data yang memiliki akurasi tinggi serta sesuai dengan kebutuhan dibutuhkan pemetaan yang tepat.

Penelitian terkait perancangan sistem basis data banyak dilakukan oleh para peneliti. Pembuatan sistem basis data yang biasa digunakan adalah untuk distribusi pasar atau data terkait pembeli sebuah usaha. Namun untuk sistem akreditasi belum ada dibuat sistem basis data yang terintegrasi. Padahal jika dianalisa lebih lanjut, data dosen yang memuat informasi kegiatan tridhama perguruan tinggi saling berkaitan antar standar penilaian. Selain itu kesalahan yang umum dilakukan oleh pelaku persiapan akreditasi adalah data yang kurang singkron, misalnya judul penelitian di dokumen rekapitulasi penelitian berbeda dengan data rekapitulasi judul yang memuat jumlah uang yang diterima untuk penelitian tersebut. Sehingga dibutuhkan suatu perancangan sistem basis data untuk mengintegrasikan seluruh standar yang terdapat pada standar akreditasi.

Seperti yang dijelaskan sebelumnya bahwa di dalam dokumen LKPS terdapat data yang saling terintegrasi sehingga terdapat potensi untuk terjadi kesalahan saat rekapitulasi, salah satunya adalah tidak sinkron antar data satu dengan yang lain. Selain itu dalam rekapitulasi membutuhkan waktu yang cukup lama, dengan adanya sistem terintegrasi dapat membantu pengguna sistem dalam proses rekapitulasi. Oleh karena itu untuk membuat sistem yang 
dapat diandalkan, dibutuhkan model sistem yang sesuai sebelum dibuat sistem basis data secara fisik. Tujuan dari penelitian ini adalah membuat konsep basis data yang dapat digunakan oleh pengguna sistem yang merupakan anggota dari tim borang akreditasi.

\section{METODE}

Penelitian ini dilakukan di ITERA dengan dokumen akreditasi yang dijadikan bahan analis merupakan dokumen akreditasi yang telah diterbitkan oleh tim BAN- PT. Penelitian yang dilakukan adalah penelitian kualitatif, yang mana sebelum merancang sebuah sistem ini dilakukan kajian terhadap dokumen akreditasi yang akan diajukan, selain itu kajian terhadap kriteria penilaian yang baru diterapkan tahun ini. Untuk memastikan apakah persepdi dari kebutuhan data atau tipe data yang digunakan dalam rekapitulasi tersebut sama dengan sistem yang akan dibuat, maka dilakukan wawancara terhadap tim pengendalian mutu institusi serta tim dari assessor yang ada di perguruan tinggi lain. Guna menghasilkan hasil output yang sesuai baik tipe data atau kebutuhan antara dokumen dengan sistem yang akan dibuat nantiny maka ditahap awal yang akan dilakukan dalam penelitian ini adalah menganalisis jumlah tabel yang ada di dokumen akreditasi. Setiap tabel tersebut juga dianalisis tipe data yang diinginkan di dokumen seperti apa. Langkah selanjutnya dilakukan normalisasi. Dalam tahap normalisasi ini dilakukan pemetaan tabel mana atau data mana yang kemungkinan memiliki keluaran yang berbeda. Teknik pengumpulan data yang dilakukan dalam penelitian ini adalah wawancara dan dokumentasi

Wawancara dibutuhkan untuk menggali informasi terkait dengan kriteria standar akreditasi yang diberlakukan mulai tahun 2019 . Di wawancara peneliti juga dapat menggali informasi terkait data mana yang memiliki keterkaitan satu sama lain. Wawancara yang dilakukan ditujukan kepada tim penjaminan mutu institusi, program studi yang akan melakukan akreditasi, dan yang terakhir jika dibutuhkan sebagai memastikan untuk memperoleh data yang diharapkan, maka wawancara dilakukan pada tim assesor yang melakukan penilaian terhadap program studi tersebut.
Dokumentasi disini adalah dengan mempelajari dokumen akreditasi program studi yang akan melakukan akreditasi dan panduan penyusunan dokumen borang akreditasi. Di dalam dokumen tersebut ditemukan data-data yang memiliki kemungkinan untuk salah, dalam artian tidak konsisten dalam memberikan informasi secara tertulis dan kebutuhan dokumen yang telah dicetak.

\subsection{Sistem Basis Data}

Database merupakan sekumpulan dari data yang terintegrasi (Elmasri \& Navathe, 2010). Sistem Database merupakan sistem komputerisasi yang bertujuan untuk menyimpan sejumlah data sehingga memudahkan pengguna untuk mendapatkan dan mengupdate informasi sesuai dengan kebutuhan Informasi yang disimpan dalam Database dapat berupa text maupun angka (Elmasri \& Navathe, 2010). Salah satu penggunaan Database dalam kehidupan sehari hari adalah pada aplikasi software pembayaran oleh kasir supermarket. Ketika melakukan pembayaran dikasir, kasir tersebut melakukan pekerjaan dengan cara menempelkan bar-code di salah satu sensor infrared. Kemudian muncul harga dari barang tersebut dalam komputer. Sehingga kasir tersebut tidak perlu mengetik ulang barang yang yang dibeli oleh pembeli tersebut.

Aplikasi pembayaran oleh kasir merupakan salah satu contoh dari penggunaan Database yang terintegrasi oleh komputer. Dalam aplikasi komputer tersebut telah terekam data-data barang beserta harga, sehingga kasir dengan mudah mendapatkan data barang serta saat melakukan input barang, maka Database tersebut secara otomatis terupdate. Salah satu keuntungan dari Database adalah dapat mempersingkat waktu pekerjaan. Sebuah Database dapat menampung data yang kompleks yang dapat digunakan secara internal maupun eksternal (Elmasri \& Navathe, 2010). Software yang digunakan oleh suatu organisasi untuk mengendalikan Database disebut dengan Database Manegement System (Okereke, 2009) atau dapat disingkat dengan DBMS. DBMS merupakan suatu kumpulan program yang memudahkan pengguna untuk membuat dan mengelola Database (Elmasri \& Navathe, 2010). Data yang ada pada DBMS dapat dimanipulasi atau dikelola dengan menggunakan query (Vavilis, Egner, \& 
Petkovic, 2015), dimana dengan query tersebut pengguna dapat mendapatkan data spesifik yang dibutuhkan, serta dapat mengupdate informasi dalam data-data tersebut.

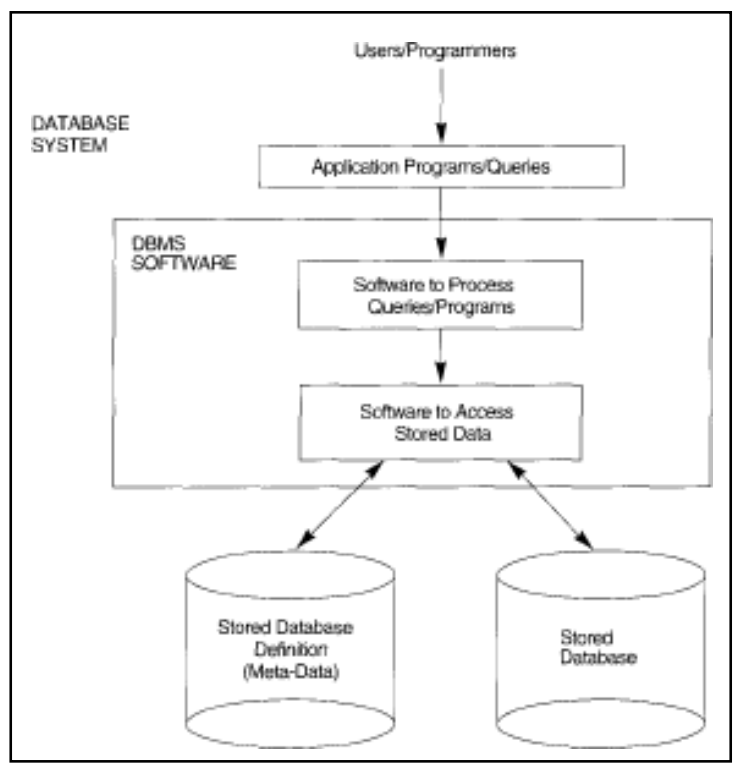

Gambar 1. Konsep integrasi sistem database (Elmasri \& Navathe, 2010)

Gambar 1 merupakan konsep dari sistem Database yang terintegrasi. Pengguna dapat mengakses Database dengan menggunakan software aplikasi dari Database. Software tersebut mengintegrasikan data-data yang telah ter- record sebelumnya, sehingga pengguna dapat dengan mudah mendapatkan, mengupdate, menghapus, atau mengelola informasi dari data yang dibutuhkan tersebut. Gambar 2 merupakan salah satu tampilan dari Database software.

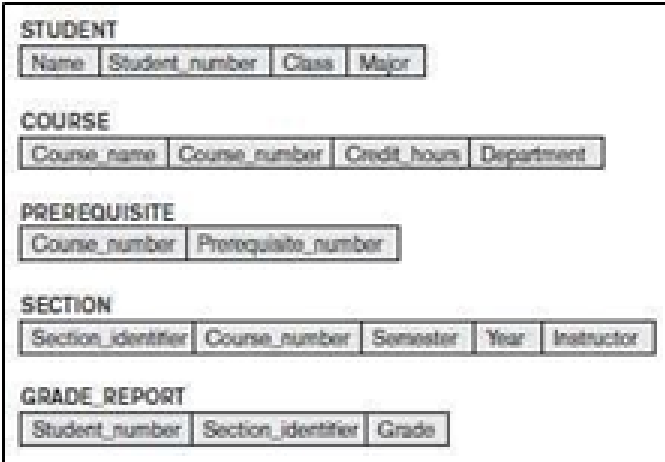

Gambar 2. Tampilan tabel software database (Elmasri dan Navathe, 2010)

\subsection{Proses Perancangan Database}

Langkah awal yang harus dilakukan ketika akan merancang suatu Database adalah dengan melakukan pengumpulan kebutuhan informasi yang dibutuhkan. Menurut Kadir (2009), informasi yang perlu digali dapat dilakukan dengan beberapa cara, antara lain: wawancara, mengamati sistem yang sedang berjalan dan mempelajari dokumen-dokumen yang tersedia. Langkah selanjutnya yang dapat dilakukan adalah dengan mengelompokkan data pada kriteria tertentu dan data-data tersebut disertai dengan hubungan. Kadir membuat suatu alur pembuatan Database yang tertera pada Gambar 3.

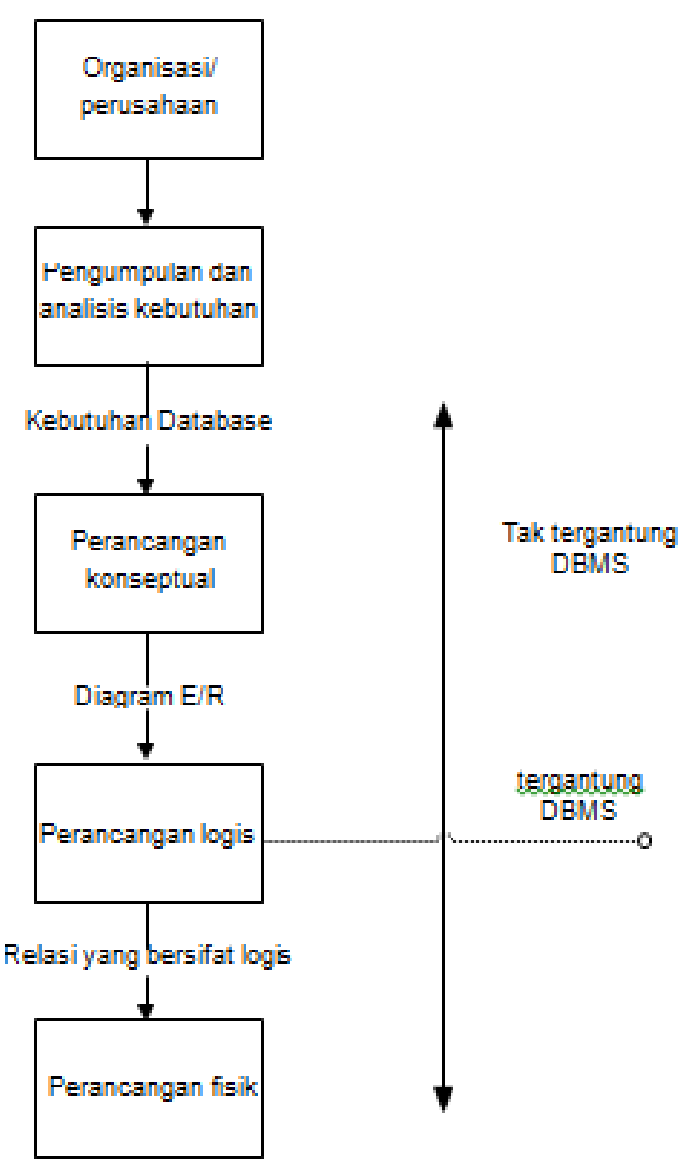

Gambar 3. Proses perancangan database (Kadir, 2009)

\subsection{Data Modelling}

Dalam merancang sebuah Database, yang perlu dilakukan adalah membuat ERD (Entity Relational Diagram) atau bisa dikenal dengan model ER. model ER merupakan suatu model yang digunakan untuk menggambarkan data dalam bentuk entitas, atribut dan hubungan antarentitas. Kadir (2009) membuat notasi dalam model ER pada Gambar 4. Sedangkan untuk kardinal hubungan antarentitas dijelaskan dalam Gambar 5. 


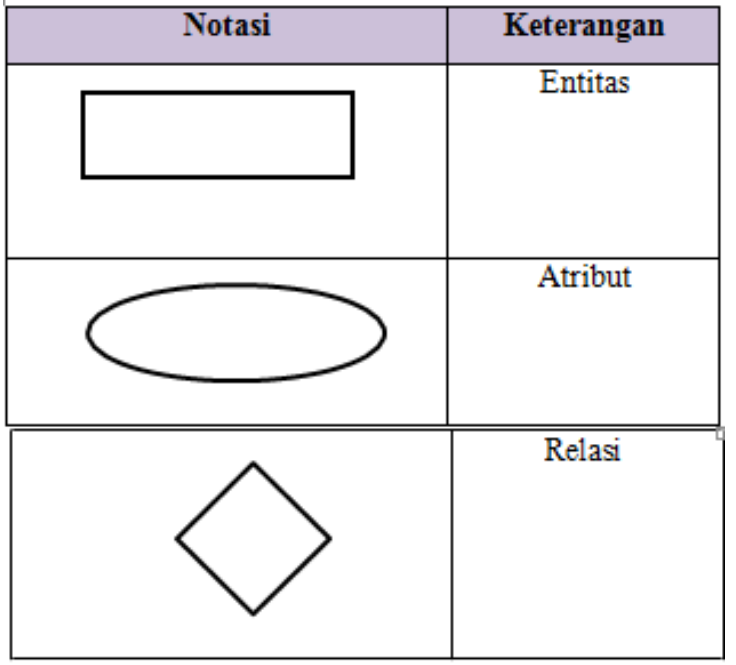

Gambar 4. Notasi yang digunakan dalam merancang model ER

\begin{tabular}{|c|l|}
\hline \multicolumn{1}{|c|}{ Kardinal Hubungan } & \multicolumn{1}{|c|}{ Keterangan } \\
\hline $\mathbf{H}$ & $\begin{array}{l}\text { Merupakan hubungan dimana antar } \\
\text { entitas hanya memiliki satu data. }\end{array}$ \\
\hline $\mathbf{W}$ & $\begin{array}{l}\text { Merupakan hubungan dimana antar } \\
\text { entitas memiliki 0 dan maksimal 1 }\end{array}$ \\
\hline $\mathbf{O}$ & $\begin{array}{l}\text { Merupakan hubungan dimana antar } \\
\text { entitas memiliki minimal 1 dan } \\
\text { maksimal sejumlah N }\end{array}$ \\
\hline & $\begin{array}{l}\text { Merupakan hubungan dimana antar } \\
\text { entitas memiliki minimal 0 dan } \\
\text { maksimal sejumlah N }\end{array}$ \\
\hline
\end{tabular}

Gambar 5. Kardinal hubungan dalam model ER

\section{HASIL DAN PEMBAHASAN}

Sesuai yang tertulis pada rancangan pelaksanaan pembuatan sistem, maka dibutuhkan pengumpulan data-data yang dibutukan untuk sistem basis data yang akan dirancang. Berdasarkan Peraturan Badan Akreditasi Nasional Perguruan Tinggi Nomor 2 Tahun 2019, terdapat dua jenis dokumen yang harus dilengkapi oleh program studi yang akan melaksanakan akreditasi, yaitu Laporan Evaluasi Diri dan Laporan Kinerja Proram Studi. Adapun standar dari Laporan Kinerja Program Studi ini antara lain (a) Indikator 1: Tata Pamong, Tata Kelola, dan Kerjasama, (b) Indikator 2: Mahasiswa, (c) Indikator 3: Sumber Daya Manusia, (d) Indikator 4: Keuangan, Sarana, dan Prasarana, (e) Indikator 5: Pendidikan, (f) Indikator 6: Penelitian, (g) Indikator 7: Pengabdian Kepada Masyarakat, (h) Indikator 8: Luaran dan Capaian Tridharma

Hasil analisa data borang akreditasi yang dianalisis terdapat 41 tabel. Di borang akreditasi 8 standar entitas yang terlibat dalam sistem adalah dosen, kurikulum, sarana dan prasarana. Dalam sistem nantinya terdapat tabel independent dan tabel dependent. Basis data yang akan dibuat nantinya adalah basis data dari dokumen akreditasi yang mengacu pada kriteria penilaian yang ada di Laporan Kinerja Program Studi.

Jumlah tabel independent adalah 8 tabel, sedangkan 22 tabel merupakan tabel dependent. Sebagai Langkah awal untuk perancangan sistem basis data adalah dilakukan normalisasi pertama. Konsep dari normalisasi pertama adalah mengubah data multivalue menjadi single-value. Dibawah ini merupakan hasil dari atribut tahapan normalisasi pertama. Dibawah

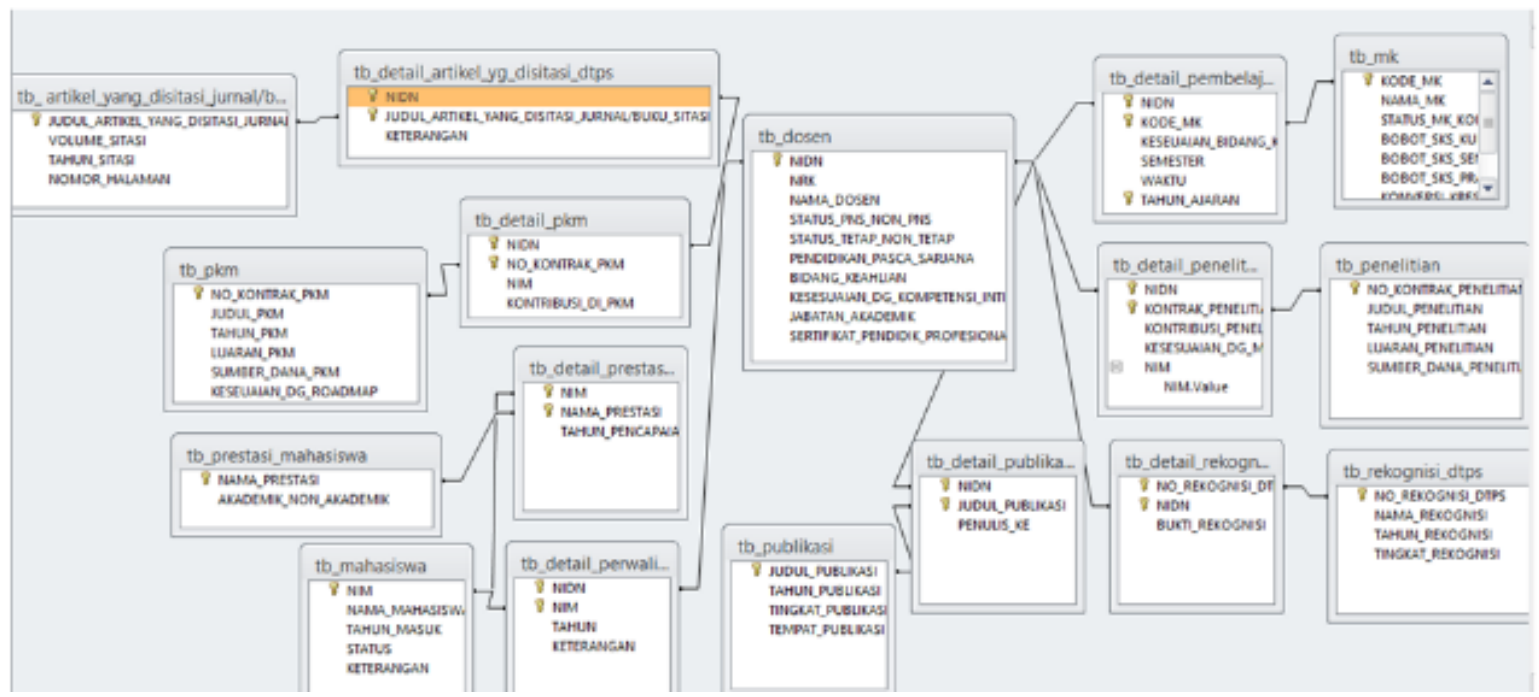

Gambar 6. Diagram entitas sistem basis data dokumen akreditasi laporan kinerja program studi 
Tabel 1. Hasil dari atribut tahapan normalisasi pertama

\begin{tabular}{l}
\hline NIDN $\rightarrow$ SUPERKEY \\
\hline NRK \\
STATUS_PNS_NON_PNS \\
STATUS_TETAP_NON_TETAP \\
PENDIDIKAN_PASCA_SARJANA \\
BIDANG_KEAHLIAN \\
KESESUAIAN_DENGAN_KOMPETENSI_INTI_PS \\
JABATAN_AKADEMIK \\
SERTIFIKAT_PENDIDIK_PROFESIONAL \\
REKOGNISI_DTPS \\
TINGKAT_REKOGNISI \\
TAHUN_REKOGNISI \\
NAMA_MK_YANG_DIAMPU_PADA_PS_YANG_DIAKREDITASI \\
KODE_MK \\
STATUS_MK_KOMPETENSI_NON_KOMPETENSI \\
BOBOT_SKS_MK \\
KESESUAIAN_BIDANG_KEAHLIAN_DG_MATA_KULIAH_YG_DIAMPU_DTPS \\
MAHASISWA_PERWALIAN \\
JUDUL_PENELITIAN \\
TAHUN_PENELITIAN \\
KONTRIBUSI_DLM_PENELITIAN \\
INTEGRASI_DENGAN_MK \\
SUMBER_DANA_PENELITIAN \\
MAHASISWA_TERLIBAT_PENELITIAN \\
LUARAN_PENELITIAN \\
JUDUL_PKM \\
KONTRIBUSI_DLM_PKM \\
SUMBER_DANA_PKM \\
LUARAN_PKM \\
MAHASISWA_TERLIBAT_PKM \\
SUMBER_DANA_PKM \\
JUDUL_ARTIKEL_YANG_DISITASI_JURNAL/BUKU_SITASI_DTPS \\
VOLUME_SITASI \\
TAHUN_SITASI \\
NOMOR_HALAMAN \\
\hline
\end{tabular}

ini merupakan hasil dari atribut tahapan normalisasi pertama, yang mana konsep dari normalisasi pertama adalah mengubah data yang bersifat multivalue menjadi single value. Sehingga didapat hasil pada Tabel 1.

Pada Normalisasi pertama dilakukan pemisahan terhadap multivalue atributte dan single-value atribut. Langkah selanjutnya adalah normalisasi kedua, yang mana di normalisasi kedua dilakukan pemisahan atribut yang memiliki ketergantungan secara fungsional. Dibawah ini merupakan hasil atrbut di tahapan normalisasi kedua. Normalisasi kedua merupakan menguraikan data yang sifatnya kebergantungan secara fungsional. Kemudian dilanjut ke normalisasi 3, yang memiliki konsep yaitu menguraikan atribut non-key memiliki kebergantungan dengan atribut lain yang non-key. Sehingga dari normalisasi ke-3 tersebut dibuat sistem secara offline dengan menggunakan microsoft access. Gambar 6 merupakan hasil normalisasi 3 yang dibuat kedalam sebuah sistem offline menggunakan microsoft access.

\section{KESIMPULAN}

Dokumen akreditasi pertahun 2019 terdapat dua jenis laporan, yaitu laporan evaluasi diri dan laporan kinerja program studi. Dari laporan kinerja program studi terdapat 2 jenis tabel, yaitu tabel independen yang mana tabel tersebut tidak memiliki keterkaitan dengan tabel yang lain, dan tabel dependen yang memiliki keterkaitan dengan yang lain. Dari penelitian yang telah dilakukan, data model yang digunakan sebagai konsep sistem basis data merupakan data dari tabel-tabel dependen. Adapun entitas utama yang memiliki keterkaitan satu sama lain adalah Dosen, Mahasiswa, Penelitian, PKM, Rekognisi Dosen, Prestasi Mahasiswa, Mahasiswa, dan Mata Kuliah.

\section{UCAPAN TERIMA KASIH}

Ucapan terima kasih penulis tujukan kepada Hibah ITERA SMART selaku sumber dana penelitian. Prof. Leo Hari Wiryanto, MS., $\mathrm{PhD}$ selaku ketua tim evaluator atas saran dan 
masukan yang diberikan selama proses penelitian ini berlangsung.

\section{DAFTAR PUSTAKA}

Aryan, W., Diana, Mohammad, S., \& Hendro., 2018, Building Scalable and Resilient Database System to Mitigate Disaster and Performance Risks, Journal of Computer Science, 466-472.

Bolchini, C., Quintarelli, E., \& Tanca, L., 2013, CARVE: Context Aware Automatic View Devinition Over Relational Databases, Journal of Information System, 45-67.

Elmasri, R., \& Navathe, S, 2010, Fundamental of Database System 4th Ed. United Stated of America: Pearson Education.
Indonesia, R, 2014, Peraturan Menteri Pendidikan dan Kebudayaan Republik Indonesia tentang Akreditasi Program Studi dan Perguruan Tinggi, Tahun 2014, Nomor 1290. Jakarta: Kementrian Pendidikan dan Kebudayaan.

Okereke, G. C., 2009, Database Management System, National Open University of Nigeria. Lagos: University of Nigeria.

Vavilis, S., Egner, A., \& Petkovic, M, 2015, An Anomaly Analysis Framework for Database System. Journal of Computer and Security, 156-173.

Wang, Y., Liu, J., He, X., \& Wang, B., 2018, Design and Realization of Rock Salt Gas Storage Database Management System Based on SQL Server. Petroleum Vol.4, 466-472. 